\title{
Prevention of Hypertension in Bangladesh: A Review
}

\author{
Tuhin Biswas $^{1}$, Sheikh Mohammed Shariful Islam ${ }^{1,2}$, Anwar Islam $^{3}$ \\ ${ }^{1}$ Center for Control of Chronic Diseases, International Center for Diarrhoeal Diseases Research, \\ Bangladesh, Dhaka, ${ }^{2}$ Center for International Health (CIH), Ludwig-Maximilians-Universität (LMU), \\ Munich, Germany, ${ }^{3}$ School of Health Policy \& Management, Faculty of Health, York University, \\ Toronto, Canada.
}

\begin{abstract}
Key Words : Prevention; Hypertension; Blood Pressure; Cardiovascular

Abstract:

Background: Hypertension is a major public health problem in both the developed and developing countries and the leading cause of morbidity and mortality globally. The risk factors for hypertension, which can largely be prevented through simple health promotion and preventive measures, are mostly known. However, evidence on strategies for prevention of hypertension in Bangladesh is not available. The aim of this review study was to identify and discuss different approaches to prevent hypertension in Bangladesh.
\end{abstract} Diseases; Bangladesh

Methods: We performed a systematic search using electronic as well as manual methods for published and unpublished reports of prevention of hypertension. We then identified and discussed prevention strategies for hypertension suitable for Bangladesh context.

Results: Several methods have shown to prevent hypertension. However, the challenge remains in implementing these methods in resource poor settings. Integrated action based on comprehensive policy and stepwise implementation should be adopted taking into consideration of local needs. Hypertension prevention should focus on awareness generation, health promotion and reduction of common risk factors using a combination of population based approach and targeted individual interventions.

Conclusion: Consorted actions should be taken as a priority to prevent hypertension through intersectoral, multidisciplinary and multilevel approach by the Government and stakeholders for creating greater awareness and healthy life-style.

(Cardiovasc. j. 2015; 7(2): 137-144)

\section{Introduction:}

Hypertension or high blood pressure (BP) is a silent killer and the most common risk factor for cardiovascular diseases (CVD), chronic kidney diseases and stroke. ${ }^{1}$ More than a quarter of the world adult population is currently hypertensive and this figure is projected to rise to $30 \%$, by $2025 .{ }^{2}$ CVDs are the leading cause of death and disability worldwide with about $80 \%$ of the deaths occurring in developing countries. ${ }^{3}$ Furthermore, the onset of hypertension and CVD occurs at a relatively younger age in Asians and consequently the age at which people die of CVD is considerably younger than in developed countries, leading to widespread social and economic hardship. ${ }^{4,5}$
The prevalence of hypertension varies considerably by country: $20 \%$ in the USA, and $25-50 \%$ in different regions in Europe. ${ }^{6}$ Reliable data related to the prevalence, incidence and mortality of hypertension are not available from Bangladesh. A meta-analysis, a population based study and a recently published survey found the prevalence of hypertension in Bangladesh 11.3\%, 18.6\%, and $20.1 \%$, respectively. ${ }^{7}$ The Bangladesh noncommunicable diseases (NCD) risk factor survey in 2010 reported the prevalence of hypertension $17.9 \%$ ( $18.5 \%$ in men and $17.3 \%$ in women). Hypertension is probably more common in the elderly population. A Bangladeshi study reported the prevalence of hypertension $65 \%$ in general,

Address of Correspondence : Dr. Sheikh Mohammed Shariful Islam, Senior Research Investigator, Center for Control of Chronic Disease (CCCD), International Center for Diarrhoeal Disease Research, Bangladesh (ICDDR,B), Dhaka, Bangladesh. Email: shariful.islam@icddrb.org 
$75 \%$ in urban and $53 \%$ in rural areas. ${ }^{8} \mathrm{~A}$ recent study among senior citizens showed that $44.8 \%$ were hypertensive. ${ }^{9}$ Another study reported that hypertension is equally prevalent in rural population and among the diabetics, the prevalence of systolic and diastolic hypertension was $23.2 \%$ and $13.6 \%$ respectively. ${ }^{10} \mathrm{~A}$ recent study by Shariful Islam and colleagues showed that systolic hypertension was significantly associated with diabetes complications [OR 0.809, 95\% CI 0.6660.981, p-value 0.031) after controlling for all other effects. ${ }^{11}$

Overweight, sedentary lifestyle, unhealthy diet, salt intake, diabetes and smoking are among the common risk factors for hypertension in Bangladesh. ${ }^{6,7}$ Hypertension and its complications, which are mostly preventable though simple health promotion and preventive measures, pose a serious threat to the health systems and socio-economic condition of a country. Hypertension prevention is therefore of great public health importance in Bangladesh and other developing countries. Several papers have described different methods of prevention of hypertension. However, papers summarizing the different approaches and effectiveness of these methods are scarce in Bangladesh. In this paper, we review and discuss the different prevention approaches for hypertension from Bangladesh context.

\section{Methods:}

The paper is based on review of published and unpublished data on prevention of hypertension in Bangladesh and other countries. A systematic search was performed using electronic as well as manual method. The electronic search was done through Pub Med, Goggle Scholar, Medline and BanglaJol. Search strategies used subject headings and key words (hypertension, prevention, Bangladesh). We also reviewed reports from different government sources, non-government organizations (NGOs) and different hospital reports in Bangladesh. References list of relevant reviews were used to identify studies and the cited literature was reviewed. Among published articles, we excluded papers that did not describe the prevention strategies of hypertension.

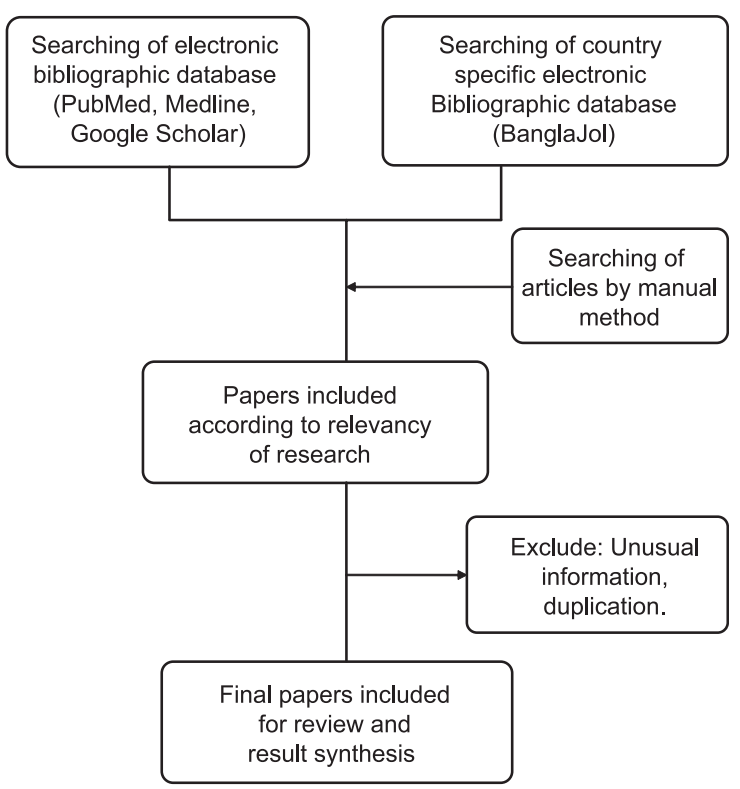

Fig-1: Steps used to sort out relevant literature

\section{Results:}

Diagnosis and screening: Hypertension often remains undiagnosed and asymptomatic. Early screening with accurate measuring devices is an important first step in the prevention of hypertension. Screening not only detects hypertension but also provides an opportunity for patient education and therapy. ${ }^{12}$ In light of the growing epidemic of CVD in the developing countries, the World Health Organization (WHO) recommends that opportunistic screening of BP is done at every visit to the physician's office. ${ }^{13}$ The diagnosis of hypertension should not be made on one single measurement in a physician's office. If $\mathrm{BP}$ is elevated, it must be reconfirmed at subsequent visits within one month unless there is a hypertensive emergency. ${ }^{14}$ According to the 7th report of the Joint National Committee on the Prevention, Detection, Evaluation, and Treatment of High Blood Pressure (JNC 7) hypertension can be classified as follows: ${ }^{15}$

\begin{tabular}{lcc}
\hline Category & $\begin{array}{c}\text { Systolic BP } \\
(\mathrm{mmHg})\end{array}$ & $\begin{array}{c}\text { Diastolic BP } \\
(\mathrm{mmHg})\end{array}$ \\
\hline Normal & $<120$ & $<80$ \\
Pre hypertension & $120-139$ & $80-89$ \\
Stage 1 hypertension & $140-159$ & $90-99$ \\
Stage 2 hypertension & $\geq 160$ & $\geq 100$ \\
\hline
\end{tabular}


In 2014, Eighth Joint National Committee on the Prevention, Detection, Evaluation, and Treatment of High Blood Pressure (JNC 8) was established to review and synthesize the latest available scientific evidence, update existing clinical recommendations, and provide guidance to busy primary care clinicians on the best approaches to manage and control hypertension in order to minimize patients' risk for CVD and other complications. The JNC 8 Committee endorsed high BP as 140/90 mmHg from the JNC 7 and suggested for all persons with hypertension, to maintain a healthy diet, weight control, and regular exercise as these lifestyle treatments have the potential to improve BP control and even reduce medication needs. ${ }^{16}$

\section{Strategies to prevent hypertension in Bangladesh}

Population-based strategy:

A population-based approach aimed at achieving a downward shift in the distribution of $\mathrm{BP}$ in the general population is an important component for any comprehensive plan to prevent hypertension. A small decrement in the distribution of systolic BP is likely to result in a substantial reduction in the burden of hypertension-related illness. In an analysis based on Framingham heart study experience, Cook and colleagues concluded that a $2 \mathrm{mmHg}$ reduction in the population average of diastolic BP for white USA residents 35 to 64 years of age would result in a 17 percent decrease in the prevalence of hypertension, a 14 percent reduction in the risk of stroke and transient ischemic attacks, and a 6 percent reduction in the risk of coronary heart diseases (CHD). ${ }^{17}$ Public health approaches, such as lowering sodium content or caloric density in the food supply, and providing attractive, safe, and convenient opportunities for exercise are ideal population-based approaches for reduction of average $\mathrm{BP}$ in the community. Enhancing access to appropriate facilities (parks, walking trails, bike paths) and to effective behavior change models is a useful strategy for increasing physical activity in the general population. ${ }^{18}$

Intensive targeted strategy:

More intensive targeted approaches, aimed at achieving a greater reduction in $\mathrm{BP}$ in those who are most likely to develop hypertension, complement the previously mentioned population based strategies for prevention of hypertension. Groups at high risk for hypertension include those with a high-normal BP, a family history of hypertension, overweight or obesity, a sedentary lifestyle, excess intake of dietary sodium and/or insufficient intake of potassium, and/or excess consumption of alcohol.

Weight loss:

A comprehensive review of the evidence supporting the value of modest reductions in body weight is provided in the clinical guidelines for the identification, evaluation, and treatment of overweight and obesity in adults. ${ }^{19}$ A study on normotensive persons participating in a phase I trials of hypertension prevention, ${ }^{20}$ showed that during the initial 18 months of active intervention those assigned to the weight loss group reduced their body weight by $7.7 \mathrm{lb}(3.5 \mathrm{~kg})$ and their systolic and diastolic BPs by 5.8 and $3.2 \mathrm{mmHg}$, respectively. After 7 years of follow up, the incidence of hypertension was 18.9 percent in the weight loss group and 40.5 percent in the control group. These findings suggest that weight loss interventions produce benefits that persist long after the cessation of the active intervention. In phase II trials of hypertension prevention, participants assigned to a weight loss counseling intervention experienced a 21 percent reduction in incidence compared with controls assigned to usual care. ${ }^{21}$ Weight loss participants who were able to lose $9.7 \mathrm{lb}(4.4 \mathrm{~kg})$ or more and to sustain this weight loss through the 36 month period of follow up experienced average reduction in systolic and diastolic BP of 5.0 and 7.0 $\mathrm{mmHg}$, respectively. ${ }^{22}$

Increased physical activity:

A meta-analysis by Whelton and colleagues showed a $4.04 \mathrm{mmHg}(95 \% \mathrm{CI}, 2.75-5.32)$ reduction in systolic BP in those assigned to aerobic exercise compared with the control group. ${ }^{23}$ The magnitude of the intervention effect appears to be independent of the intensity of the exercise program. In the physical activity and health: a report of the surgeon general, it is recommended that persons exercise for at least 30 minutes on most, if not all, days of the week .

Dietary sodium reduction:

At least three meta-analysis of the efficacy of reduced sodium intake in lowering $\mathrm{BP}$ have been published since 1993. ${ }^{15,24,25}$ In all three reports, sodium reduction was associated with a small but significant reduction in systolic BP in normotensive persons. In a meta-analysis of 12 randomized controlled trials conducted in 1,689 normotensive participants, Cutler and colleagues estimated that 
an average reduction of $77 \mathrm{mmol} / \mathrm{d}$ in dietary intake of sodium resulted in a $1.9 \mathrm{mmHg}(95 \% \mathrm{CI}, 1.2-$ $2.6 \mathrm{mmHg}$ ) decrement in systolic BP and a 1.1 $\mathrm{mmHg}(95 \% \mathrm{CI}, 0.6-1.6 \mathrm{mmHg})$ decline in diastolic BP. ${ }^{24}$

In a randomized controlled trial (dietary approaches to stop hypertension [DASH]-sodium trial) conducted in 412 persons with an average systolic BP of 120 to $159 \mathrm{mmHg}$ and an average diastolic BP of 80 to $95 \mathrm{mmHg}$, a reduction in sodium intake from a high level (mean urinary sodium excretion, $142 \mathrm{mmol} / \mathrm{d}$ ) to an intermediate level (mean urinary sodium excretion, $107 \mathrm{mmol} /$ d) reduced systolic BP by $2.1 \mathrm{mmHg}(\mathrm{p}<0.001)$ during consumption of a usual American control diet and by $1.3 \mathrm{mmHg}(\mathrm{p}=.03)$ during consumption of a DASH-diet that was high in fruits and vegetables and low fat dairy products. ${ }^{20}$ Reducing sodium intake from the intermediate level to a lower level (mean urinary sodium excretion, 65 $\mathrm{mmol} / \mathrm{d}$ ) resulted in an additional reduction in systolic $\mathrm{BP}$ of $4.6 \mathrm{mmHg}$ during consumption of the control diet $(p<0.001)$ and $1.7 \mathrm{~m} \mathrm{mmHg}$ reduction during consumption of the dash diet $(p<0.01)$. The effects of sodium reduction were greater for those who ate the typical American diet, compared with those on the dash diet. These findings are consistent with current national recommendations for a moderately low intake of dietary sodium (no more than $100 \mathrm{mmol} / \mathrm{d}$ : approximately $<6 \mathrm{~g}$ of sodium chloride or $<2.4 \mathrm{~g}$ of sodium per day) by all Americans and suggest that an even lower level of dietary sodium intake may result in a greater reduction in $\mathrm{BP} .{ }^{25}$ In a large, long-term community-based randomized controlled trial, Whelton and colleagues reported that a moderate reduction of dietary sodium intake resulted in an additional $4.3 \mathrm{mmHg}$ reduction in systolic BP among older.

Persons with hypertension whose BPs were well controlled by a single antihypertensive medication and for those assigned to a combined sodium reduction and weight loss intervention, the corresponding additional reduction in systolic BP was $5.5 \mathrm{mmHg} .{ }^{26}$ The need for antihypertensive medication during a subsequent 18 month period of follow up was reduced by $31 \%$ and $53 \%$ in those assigned to sodium reduction and combined sodium reduction and weight loss, respectively. In the NHANES epidemiologic follow-up study, it was reported that a $100 \mathrm{mmol}$ higher level of sodium intake in overweight persons was associated with a $32 \%$ increase in stroke incidence, $89 \%$ increase in stroke mortality, $44 \%$ increase in CHD mortality, 61\% increase in CVD mortality, and 39\% increase in mortality from all causes. ${ }^{27}$ In Finland a prospective population-based cohort study showed that the hazard ratios for CHD, CVD, and all-cause mortality, associated with a $100 \mathrm{mmol}$ higher level of $24 \mathrm{~h}$ urinary sodium excretion, were 1.51 (95\% CI, 1.14-2.00), 1.45 (95\% CI, 1.14-1.84), and 1.26 (95\% CI, $1.06-1.50)$, respectively. ${ }^{28}$ There was a significant interaction between sodium excretion and body mass index for CVD and total mortality, with sodium being a stronger predictor of mortality in men who were overweight. These data support the premise that a lower intake of dietary sodium reduces the risk of hypertension and subsequent CVD, especially in those who are also overweight.

Potassium supplementation:

Clinical trials and meta-analysis indicate that potassium supplementation lowers BP in both hypertensive and normotensive persons. In a metaanalysis of the results from 12 trials with 1,049 normotensive participants, Whelton et al. reported that potassium supplementation (median, 75 $\mathrm{mmol} / \mathrm{d})$ lowered systolic BP by $1.8 \mathrm{mmHg}(95 \%$ CI, 0.6-2.9) and Diastolic BP by $1.0 \mathrm{mmHg}(95 \%$ CI, $0.0-2.1.){ }^{29}$ The effects of potassium supplementation appeared greater in those with higher levels of sodium intake.

Dietary measures:

The DASH and DASH-sodium trials used dietary interventions that incorporated several nutritional recommendations for lowering $\mathrm{BP} .{ }^{25,30}$ In the 8week DASH trial, study participants with a systolic $\mathrm{BP}$ less than $160 \mathrm{mmHg}$ and a diastolic BP between 80 and $95 \mathrm{mmHg}$ level of urinary sodium excretion $(141 \mathrm{mmol} / \mathrm{d})$. A significant reduction in diastolic BP was also observed. Furthermore, the beneficial effects of the DASH diet and the DASH -sodium diet with reduced sodium broadly in all major subgroups of the population. ${ }^{6}$

Calcium supplementation:

Consistent with previous observations, a recent meta analysis of randomized controlled clinical trials suggests that calcium supplementation results in only a small reduction in $\mathrm{BP}$ and this effect has only been observed in those with 
hypertension. ${ }^{30}$ However, for general health, adequate calcium intake $(1,000-1,200 \mathrm{mg} / \mathrm{d}$ for adults) as a dietary component is recommended. ${ }^{31}$

Fish oil supplementation:

Two meta-analysis of clinical trials indicate that supplementation with relatively high doses of omega-3 polyunsaturated fatty acids (omega- 3 pufa) lowers BP in hypertensive patients, especially in those with untreated hypertension. In normotensive persons, however, the effect seems to be small. In a pooled analysis of 11 trials with 728 normotensive participants, Appel and colleagues reported that fish oil supplementation ( $3.4 \mathrm{~g} / \mathrm{d}$ ) lowered systolic BP by only $1.0 \mathrm{mmHg}$ (95 percent ci, 0.0-2.0) and diastolic $\mathrm{BP}$ by $0.5 \mathrm{mmHg}$ (95\% CI, -0.2-1.2). Adverse effects, including eructation and a fishy taste, were more common in those assigned to fish oil capsules. Although evidence for a BP-lowering effect of fish oil is modest, observational epidemiological studies and clinical trials have suggested that an increased intake of fish oil may reduce the risk of CHD and stroke. ${ }^{32-34}$

Herbal supplements:

There has been considerable increase in the use of herbal products in the United States. Results from the 1998-1999 Slone survey indicated that about $14 \%$ of the US adults were taking herbal products. ${ }^{35}$ The 10 most commonly used herbal products are ginseng, ginko biloba extract, allium sativum, glucosamine, St. John's wort, echinacea augustifolia,lecithin, chondroitin, creatine, and serenoa repens. ${ }^{33}$ Dietary supplements including herbals do not undergo the same stringent regulatory approval process as drugs. Food and drug laws do not require demonstration of safety and efficacy to support legal marketing of dietary supplements. There is a lack of standardization among brands of supplements, and the bioactive ingredient of products can vary widely. Few clinical trial reports are available to support the use of herbal supplements in the prevention or treatment of high BP or heart disease. Health care professionals should ask their patients about the use of herbal products and consider the possibility of herb-drug interactions.

Primary prevention in children:

There is ample evidence that hypertension begins in childhood. Children with higher than average
BP levels early in life are more likely to develop hypertension later in life. Efforts to prevent BP from increasing in childhood are prudent and best accomplished by application of the same lifestyle approaches used to prevent and treat hypertension in adults. ${ }^{36}$ Accordingly, school administrators are encouraged to examine their lunch menus and promote the use of heart healthy foods. Parents are encouraged to read food labels and make wise choices for lunches prepared at home. In addition, school curricula should include health education programs that promote healthy life style.

\section{Barriers and challenges in Bangladesh}

Less than a third of hypertensive patients receive recommended levels of treatment even in rich and developed nations. ${ }^{37}$ Low levels of awareness and inadequacy of treatment are of an even greater magnitude in the developing world particularly in Bangladesh. This underscores the large gap between available evidence and clinical practice that could be improved to reduce the widespread health consequences of uncontrolled hypertension particularly in the Bangladesh.

Hypertensive patients in Bangladesh have a close association with dyslipidemia and need measurement of blood pressure and lipid profile at regular intervals to prevent car-diovascular disease, stroke, and other comorbidities. ${ }^{38}$

\section{Economic burden}

Economic information of a disease is important for future planning and resource allocation. ${ }^{39}$ However data on the economic burden of hypertension and cost-effectiveness of prevention strategies are not available in Bangladesh. Multiplicity of health care providers including alternative caregivers, lack of capacity and affordability of physician services in our country adversely impacts hypertension prevention and management. Patients often pay out-of-pocket for their health care. ${ }^{40}$ Besides imposing considerable economic burden, this often drives many families into poverty particularly those with chronic conditions such as hypertension requiring lifelong care. Developing country-specific information on disease burden and costs, information that demonstrates resource needs to support scaling up of hypertension prevention strategies are needed. 


\section{Prevention of hypertension in the community} The major thrust of management of hypertension in a developing country settings such as Bangladesh should be on primary prevention efforts through a comprehensive population based approach directed at lifestyle changes (a healthy appropriate calorie diet which is low in saturated fat and salt additives and rich in fruits and vegetables, increased physical activity, and a smoking free society), properly balanced with a high risk approach of cost effective clinical care. The health care delivery system needs to emphasize early detection and treatment of individual patients at high risk with the most cost effective drugs. Existing networks of primary health care centers should be optimally utilized and categories of healthcare providers, who can detect, educate and monitor hypertensive patients can be expanded to include nurses and multipurpose health workers. Though the current networks focus primarily on communicable diseases and reproductive health, networks could be used for opportunistic screening for hypertension and CVD risk assessment. A good model in optimal use of existing services for hypertension management was reported from South Africa, where a nurse led clinical protocol based in primary care clinics succeeded in achieving hypertension control in $68 \%$ of patients.

\section{Limitations:}

Data related to hypertension in Bangladesh are often insufficient, suffer from statistical flaws, and are not readily available. Many articles were published in local, non indexed journals, not available online, and difficult to gather. In literature review we included only papers in English. Further studies analyzing the costeffectiveness of interventions to prevent hypertension in Bangladesh and other countries would provide better evidence.

\section{Conclusion:}

Hypertension is one of the leading causes of morbidity and mortality in Bangladesh. Although several methods have shown to prevent hypertension, the challenge remains in implementing these methods in resource poor settings. Integrated action based on comprehensive policy and stepwise implementation should be adopted taking into consideration of local needs. Hypertension prevention should focus on awareness generation, health promotion and reduction of common risk factors using a combination of population based approach and targeted individual interventions. Consorted actions should be taken as a priority to prevent hypertension through intersectoral, multidisciplinary and multilevel approach by the Government, NGOs and civil societies creating greater awareness for a healthy life-style adoption.

\section{Conflict of Interest - None.}

\section{Acknowledgements}

We would like to thank all the Faculty, Course on Advanced Research Methodology (CARM) at the Center for Control of Chronic Diseases at ICDDR, B for supporting this study. ICDDR, B acknowledges with gratitude the commitment of its donors for their generous support to its research efforts. The content of this paper is solely the responsibility of the authors and does not necessarily represent the official views of their employing institution.

\section{References:}

1. Fuster V, Voute J, Hunn M, Smith SC. Low Priority of Cardiovascular and Chronic Diseases on the Global Health Agenda A Cause for Concern. Circulation 2007;116(17):1966-1970.

2. Martiniuk AL, Lee CM, Lawes CM, Ueshima H, Suh I, Lam TH, et al. Hypertension: its prevalence and population-attributable fraction for mortality from cardiovascular disease in the Asia-Pacific region. $J$ Hypertens 2007;25(1):73-79.

3. Alwan A, MacLean DR, Riley LM, d'Espaignet ET, Mathers CD, Stevens GA, et al. Monitoring and surveillance of chronic non-communicable diseases: progress and capacity in high-burden countries. Lancet 2010;376(9755):1861-1868.

4. Mohan S, Campbell N, Chockalingam A. Management of hypertension in low and middle income countries: Challenges and opportunities. Prevention and Control 2005;1(4):275-284.

5. Islam SMS, Purnat TD, Phuong NTA, Mwingira U, Schacht K, Fröschl G. Non Communicable Diseases (NCDs) in developing countries: a symposium report. Globalization and health 2014;10(1):81.

6. Obarzanek E, Proschan MA, Vollmer WM, Moore TJ, Sacks FM, Appel LJ, et al. Individual Blood Pressure Responses to Changes in Salt Intake Results From the DASH-Sodium Trial. Hypertension 2003;42(4):459-467.

7. Zaman M. Prevalence of hypertension in a Bangladeshi adult population. J Hum Hypertens 1999;13:547-549. 
8. Islam A, Majumder AA. Hypertension in Bangladesh: a review. Indian heart journal 2012;64(3):319-323.

9. Moni M, Rahman M, Haque M, Islam M, Ahmed K. Blood pressure in relation to selected anthropometric measurements in senior citizens. Mymensingh Med $J$ 2010;19(2):254-258.

10. Tabassum R, Begum N, Ferdousi S, Begum S, Ali T. Heart rate variability in patients with essential hypertension. J Bangladesh Soc Physiol 2010;5(1):1-7.

11. Islam SMS, Alam DS, Wahiduzzaman M, Niessen LW, Froeschl G, Ferrari U, et al. Clinical characteristics and complications of patients with type 2 diabetes attending an urban hospital in Bangladesh. Diabetes \& Metabolic Syndrome: Clinical Research \& Reviews 2014;8(1).

12. Dalal S, Beunza JJ, Volmink J, Adebamowo C, Bajunirwe F, Njelekela M, et al. Non-communicable diseases in sub-Saharan Africa: what we know now. Int J Epidemiol 2011;40(4):885-901.

13. Paris J, Wakeman A, Griffiths R. General practitioners and public health. Public health 1992;106(5):357-366.

14. Kaplan NM. Kaplan's clinical hypertension. Philadelpia: Lippincott Williams \& Wilkins, 2010.

15. Chobanian AV, Bakris GL, Black HR, Cushman WC, Green LA, Izzo JL, et al. Seventh report of the joint national committee on prevention, detection, evaluation, and treatment of high blood pressure. Hypertension 2003;42(6):1206-1252.

16. James PA, Oparil S, Carter BL, Cushman WC, Dennison-Himmelfarb C, Handler J, et al. 2014 evidence-based guideline for the management of high blood pressure in adults: report from the panel members appointed to the Eighth Joint National Committee (JNC 8). JAMA 2014;311(5):507-520.

17. Cook NR, Cohen J, Hebert PR, Taylor JO, Hennekens $\mathrm{CH}$. Implications of small reductions in diastolic blood pressure for primary prevention. Arch Intern Med 1995;155(7):701-709.

18. Whelton PK, He J, Appel LJ, Cutler JA, Havas S, Kotchen TA, et al. Primary prevention of hypertension: clinical and public health advisory from The National High Blood Pressure Education Program. JAMA 2002;288(15):1882-1888.

19. Orzano AJ, Scott JG. Diagnosis and treatment of obesity in adults: an applied evidence-based review. J Am Board Fam Pract 2004;17(5):359-369.

20. He J, Whelton PK, Appel LJ, Charleston J, Klag MJ. Long-term effects of weight loss and dietary sodium reduction on incidence of hypertension. Hypertension 2000;35(2):544-549.

21. Group ToHPCR. Effects of weight loss and sodium reduction intervention on blood pressure and hypertension incidence in overweight people with high- normal blood pressure: the Trials of Hypertension Prevention, phase II. Arch Intern Med 1997;157(6):657.

22. Stevens VJ, Obarzanek E, Cook NR, Lee I-M, Appel LJ, West DS, et al. Long-term weight loss and changes in blood pressure: results of the Trials of Hypertension Prevention, phase II. Ann Intern Med 2001;134(1):1-11.

23. Whelton SP, Chin A, Xin X, He J. Effect of aerobic exercise on blood pressurea meta-analysis of randomized, controlled trials. Ann Intern Med 2002;136(7):493-503.

24. Cutler JA, Follmann D, Allender PS. Randomized trials of sodium reduction: an overview. Am J Clin Nutr 1997;65(2):643S-651S.

25. Graudal NA, Galløe AM, Garred P. Effects of sodium restriction on blood pressure, renin, aldosterone, catecholamines, cholesterols, and triglyceride: a metaanalysis. JAMA 1998;279(17):1383-1391.

26. Whelton PK, Appel LJ, Espeland MA, Applegate WB, Ettinger Jr WH, Kostis JB, et al. Sodium reduction and weight loss in the treatment of hypertension in older persons: a randomized controlled trial of nonpharmacologic interventions in the elderly (TONE). JAMA 1998;279(11):839-846.

27. Appel LJ, Brands MW, Daniels SR, Karanja N, Elmer PJ, Sacks FM. Dietary approaches to prevent and treat hypertension a scientific statement from the American Heart Association. Hypertension 2006;47(2):296-308.

28. Tuomilehto J, Jousilahti P, Rastenyte D, Moltchanov V, Tanskanen A, Pietinen P, et al. Urinary sodium excretion and cardiovascular mortality in Finland: a prospective study. Lancet 2001;357(9259):848-851.

29. Whelton PK, He J, Cutler JA, Brancati FL, Appel LJ, Follmann D, et al. Effects of oral potassium on blood pressure: meta-analysis of randomized controlled clinical trials. JAMA 1997;277(20):1624-1632.

30. Appel LJ, Moore TJ, Obarzanek E, Vollmer WM, Svetkey LP, Sacks FM, et al. A clinical trial of the effects of dietary patterns on blood pressure. N Eng J Med 1997;336(16):1117-1124.

31. Yates AA, Schlicker SA, Suitor CW. Dietary reference intakes: the new basis for recommendations for calcium and related nutrients, B vitamins, and choline. J Am Diet Assoc 1998;98(6):699-706.

32. Appel LJ, Miller ER, Seidler AJ, Whelton PK. Does Supplementation of Diet With'Fish Oil'Reduce Blood Pressure?: A Meta-analysis of Controlled Clinical Trials. Arch Intern Med 1993;153(12):1429-1438.

33. Ascherio A, Rimm EB, Stampfer MJ, Giovannucci EL, Willett WC. Dietary intake of marine n-3 fatty acids, fish intake, and the risk of coronary disease among men. N Eng J Med 1995;332(15):977-983. 
34. Dehmer GJ, Popma JJ, van den Berg EK, Eichhorn EJ, Prewitt JB, Campbell WB, et al. Reduction in the rate of early restenosis after coronary angioplasty by a diet supplemented with $\mathrm{n}-3$ fatty acids. $N$ Eng $J$ Med 1988;319(12):733-40.

35. Kaufman DW, Kelly JP, Rosenberg L, Anderson TE, Mitchell AA. Recent patterns of medication use in the ambulatory adult population of the United States: the Slone survey. JAMA 2002;287(3):337-344.

36. Kavey R-EW, Daniels SR, Lauer RM, Atkins DL, Hayman LL, Taubert K. American Heart Association guidelines for primary prevention of atherosclerotic cardiovascular disease beginning in childhood. Circulation 2003;107(11):1562-1566.
37. Starfield B, Shi L, Macinko J. Contribution of primary care to health systems and health. Milbank Quarterly 2005;83(3):457-502.

38. Choudhury KN, Mainuddin A, Wahiduzzaman M, Islam SMS. Serum lipid profile and its association with hypertension in Bangladesh. Vascular Health and Risk Management 2014;10:327.

39. Islam SMS, Lechner A, Ferrari U, Froeschl G, Niessen LW, Seissler J, et al. Social and economic impact of diabetics in Bangladesh: protocol for a case-control study. BMC Public Health 2013;13(1):1217.

40. Van Doorslaer E, O'Donnell O, Rannan-Eliya RP, Somanathan A, Adhikari SR, Garg CC, et al. Effect of payments for health care on poverty estimates in 11 countries in Asia: an analysis of household survey data. Lancet 2006;368(9544):1357-1364. 